\title{
Serum hepatitis B surface antigen titer and transient elastography in screening for insignificant fibrosis in $\mathrm{HBeAg}$-positive chronic hepatitis $\mathrm{B}$ patients
}

This article was published in the following Dove Press journal:

Therapeutics and Clinical Risk Management

13 February 2015

Number of times this article has been viewed

\section{Ling-Bo Liang \\ Xia Zhu \\ Li-Bo Yan \\ Ling-Yao Du \\ Cong Liu \\ Li-Yu Chen \\ Juan Liao \\ Hong Tang}

Center of Infectious Disease, West China Hospital, West China School of Medicine, and State Key Laboratory of Biotherapy, Sichuan University, Chengdu, People's Republic of China
Correspondence: Hong Tang Center of Infectious disease and State Key Laboratory of Biotherapy, West China Hospital, West China School of Medicine, Sichuan University, 37\# Guoxue Lane, Chengdu 6I004I, People's Republic of China

Tel +862885423052

Fax +8628 85423052

Email htang6198@hotmail.com
Objective: To explore the predictive value of serum hepatitis B surface antigen (HBsAg) titer and transient elastography in screening for insignificant fibrosis in hepatitis B e antigen (HBeAg)-positive chronic hepatitis B patients.

Methods: We conducted a cross-sectional study of eligible patients treated from March 2012 to May 2013 at the West China Hospital of Sichuan University. Eligible patients underwent liver transient elastography and liver biopsy. We assessed the serum HBsAg level, serum hepatitis B virus (HBV) deoxyribonucleic acid (DNA) level, HBV genotypes, liver stiffness measurement (LSM) values by transient elastography, and histological fibrosis staging by METAVIR classification.

Results: A total of 129 consecutive patients were recruited. The LSM value $(P<0.001$, odds ratio $14.67,95 \%$ CI $0.158-0.551)$ and $\log _{10} \mathrm{HBsAg}(P=0.045$, odds ratio $4.03,95 \% \mathrm{CI}$ $0.136-0.976)$ correlated with a liver fibrosis score $<F 2$, independently. Inverse correlations were found between $\log _{10} \mathrm{HBsAg}$ and the LSM value $(r=-576, P<0.001)$ and fibrosis staging $(r=-374, P<0.001)$. Patients with a fibrosis score $<$ F2 had a significantly higher $\log _{10} \mathrm{HBsAg}$ than patients with a fibrosis score $\geq \mathrm{F} 2$ among those with an LSM value under $9.4 \mathrm{kPa}(4.6 \pm 0.7$ vs $4.3 \pm 0.5, P=0.006)$. The HBsAg titer achieved an area under the receiver operating characteristic curve of $0.758(P<0.001,95 \%$ CI $0.631-0.884)$ in predicting a fibrosis score $<\mathrm{F} 2$, with a cut-off value of $10,400 \mathrm{IU} / \mathrm{mL}$, a positive predictive value of $73 \%$, and a negative predictive value of $79 \%$.

Conclusion: In $\mathrm{HBeAg}$-positive patients with an alanine aminotransferase level $<2 \times$ the upper limit of normal, high serum HBsAg levels can predict a fibrosis score $<$ F2, and a lower HBsAg titer could be supportive of early fibrosis in patients with an LSM value under $9.4 \mathrm{kPa}$.

Keywords: hepatitis B e antigen, HBsAg, HBV

\section{Introduction}

More than 350 million people are infected chronically with hepatitis B virus (HBV) worldwide, ${ }^{1}$ and in the Chinese population of 1.3 billion individuals, there are estimated to be 93 million HBV carriers. Each year 300,000 deaths can be attributed to the progression of liver diseases such as cirrhosis, liver failure, and hepatocellular carcinoma in $\mathrm{HBV}$-infected patients. ${ }^{2} \mathrm{HBV}$ replicates its genome via an RNA intermediate. ${ }^{3}$ The transcriptional template of $\mathrm{HBV}$ is the covalently closed circular (ccc) deoxyribonucleic acid (DNA) existing in the nuclei of hepatocytes. ${ }^{4,5}$ Hepatitis B surface antigen (HBsAg), the glycosylated envelope protein of the mature $\mathrm{HBV}$ virion, is translated from two $\mathrm{HBV}$ messenger ribonucleic acid (mRNA) transcripts, pre-S1 mRNA and pre-S2/S mRNA, whereas HBV DNA replicates via a different RNA transcript, the pregenomic RNA. Therefore, HBsAg production 
and viral replication can be considered as two different processes. ${ }^{6}$ Because nucleos $(t)$ ide analogue therapy selectively inhibits virion production by targeting the HBV reverse transcriptase but does not reduce HBsAg levels, the HBsAg titer theoretically should better reflect the cccDNA level and the transcriptional activity of cccDNA than serum HBV DNA level. ${ }^{5}$ Indeed, recent studies have shown that HBsAg titer correlates well with intrahepatic cccDNA levels before and after antiviral therapy, especially in hepatitis $\mathrm{B}$ e antigen ( $\mathrm{HBeAg}$ )-positive patients. ${ }^{7,8}$ Therefore, the quantitative serum HBsAg level represents a new potential marker for predicting the prognosis of chronic HBV infection.

Liver fibrosis, the natural healing process of liver necroinflammation, is the essential pathogenic process that can lead to cirrhosis. ${ }^{9}$ Therefore, it is important to detect fibrosis in the early stages. Liver biopsy is generally considered to be the gold standard for assessing liver fibrosis. However, this method is limited by its invasive nature, the risk of serious complications, ${ }^{10}$ and the low acceptability. Hence, several noninvasive methods have been developed for predicting liver fibrosis. ${ }^{11-13}$ However, the investigations presenting these methods are limited by the small size of the studied populations and the use of serum markers not routinely available in standard laboratories. Transient elastography (FibroScan) is a noninvasive and reproducible method for assessing fibrosis and has been reported to be reliable for detecting advanced liver fibrosis and early cirrhosis according to two meta-analyses. ${ }^{14,15}$ However, it has reduced diagnostic accuracy with lower fibrosis scores. ${ }^{16}$ Recently, a study in France suggested that lower HBsAg is associated with more severe liver fibrosis in HBeAg-positive patients, ${ }^{17}$ and other investigators found that high HBsAg levels correlate with insignificant fibrosis in HBeAg-positive patients. ${ }^{18}$ These findings are important, because the HBV DNA level has no association with the severity of liver fibrosis. ${ }^{18,19}$ However, the association between HBsAg titer and transient elastography remains undiscovered. Because liver stiffness measurement (LSM) has limited diagnostic accuracy for early fibrosis, it is important to find a new method for screening minimal fibrosis in the early stage, and thus reducing the need for liver biopsy. Therefore, the aim of this study was to evaluate the association between HBsAg titer and LSM value as well as histological fibrosis score in treatment-naïve $\mathrm{HBeAg}$-positive patients with a serum alanine aminotransferase (ALT) $<2 \times$ the upper limit of normal (ULN), especially those patients with a low LSM value who are generally considered to not have liver fibrosis.

\section{Patients and methods Study design and eligibility patients}

This cross-sectional study included eligible consecutive patients with HBsAg positivity for at least 6 months who were regularly followed at the Center of Infectious Disease, West China Hospital of Sichuan University from March 2012 to May 2013. All recruited patients were examined by clinicians, and the inclusion criteria were as follows: (i) age 18-65 years; (ii) presence of HBsAg in the serum for at least 6 months; and (iii) availability of records of patients' demographics, liver biochemistries, HBV DNA levels, and HBV genotypes. The exclusion criteria were as follows: (i) infection with hepatitis $\mathrm{A}$, hepatitis $\mathrm{C}$, hepatitis $\mathrm{D}$, hepatitis $\mathrm{E}$, or human immunodeficiency virus; (ii) liver cirrhosis or hepatocellular carcinoma; (iii) serum ALT level $\geq 2 \times$ ULN; (iv) jaundice caused by obstructive or hemolytic diseases; (v) prolonged prothrombin time induced by blood system diseases; (vi) drug hepatitis, Wilson disease, alcohol-related liver disease, and autoimmune hepatitis; (vii) comorbid condition, uncontrolled metabolic condition or psychiatric condition; and (viii) treatment with antiviral therapy or use of antiviral drugs within the previous 6 months. The study protocol was prepared in accordance with the ethical guidelines of the 1995 Declaration of Helsinki and was approved by the independent ethics committees of West China Hospital of Sichuan University. In addition, all patients provided written consent prior to liver biopsy.

\section{Quantitative serum $\mathrm{HBsAg}$ titer}

Serum HBsAg levels were quantified using a commercial chemiluminescent microparticle immunoassay (ARCHITECT, Abbott Laboratories, Abbott Park, IL, USA) with a diagnostic range of 0.05-250 IU/mL. Serial 1:500 dilutions were performed if the HBsAg titers were $>250 \mathrm{IU} / \mathrm{mL}$, according to the manufacturer's instructions.

\section{Liver transient elastography}

All patients consented to two sets of liver transient elastography by FibroScan (Echosens, Paris, France) when enrolled. The two LSM values were obtained by two independent, trained operators blinded to each other's results and to other measurements. An ultrasonic transducer probe mounted on the axis of a vibrator was placed in the patient's intercostal space over the right lobe of the liver. A vibration pulse of mild amplitude and low frequency was transmitted to the liver by the transducer to induce an elastic shear wave through the liver. Each vibration pulse provides a LSM value measured in kiloPascals $(\mathrm{kPa})$ that indicates the stiffness of the liver. 
At least ten valid LSM values were acquired for each patient, and the median value was calculated. Measurements with a success rate of $<60 \%$ were considered as failures. The median LSM values with an interquartile range $>30 \%$ median value also were excluded. The final LSM value was the average of the median LSM values obtained by the two operators. Classification of LSM values was based on the recommendations by the Review Panel for Liver Stiffness Measurement of China: ${ }^{20}$ for chronic hepatitis B patients, LSM values less than $9.4 \mathrm{kPa}$ were considered indicative of no or insignificant fibrosis; LSM values between $9.4 \mathrm{kPa}$ and $12.4 \mathrm{kPa}$ were considered indicative of significant fibrosis; LSM values between $12.4 \mathrm{kPa}$ and $17.5 \mathrm{kPa}$ were considered indicative of advanced fibrosis; and LSM values greater than $17.5 \mathrm{kPa}$ were considered indicative of cirrhosis.

\section{Liver biopsy}

Percutaneous liver biopsy was performed using a 16-gauge needle (Bard, Germany, 1620) according to the standard Menghini technique. Liver histology was assessed by a pathologist blinded to all other data. Liver biopsy specimens were prepared by hematoxylin and eosin staining, Masson trichrome staining, and reticulin staining for histological assessment. Only specimens of more than $15 \mathrm{~mm}$ and with greater than six portal tracts were accepted for histological analysis. Specimens were staged for fibrosis according to the METAVIR classification: no fibrosis (F0); portal fibrosis without septa (F1); portal fibrosis with few septa (F2); numerous septa without cirrhosis (F3); and cirrhosis (F4). Insignificant fibrosis was defined as a METAVIR score of 0 or 1 ; significant fibrosis was defined as a METAVIR score of 2 or 3 , and liver cirrhosis was defined as a METAVIR score of 4.

\section{Statistical analyses}

All statistical analyses were performed using SPSS version 17.0 (SPSS, Chicago, IL, USA). Descriptive values were expressed as mean \pm standard deviation or percentage, as appropriate. One-way analysis of variance was used for data comparison between continuous variables. Chi-square test was used for data comparison between categorical variables. Pearson's correlations were used to evaluate the associations between $\log _{10} \mathrm{HBsAg}$ and the LSM value. Spearman's correlations were used to evaluate the associations between $\log _{10} \mathrm{HBsAg}$ and the historical fibrosis score. Receiver operating characteristic (ROC) curve analysis was used to determine the best cut-off level of serum HBsAg titer for the prediction of liver fibrosis. Multiple regression analyses were used to identify predictors of liver fibrosis.
The $P$-values were two-tailed, and $P<0.05$ was considered statistically significant.

\section{Results \\ Patient characteristics}

The baseline characteristics at the time of liver biopsy and LSM are summarized in Table 1 . The mean age of the 129 patients (93 males, 36 females) was 31.5 \pm 6.6 years (range, 18-58 years). There were 87 patients infected with genotype B HBV and 42 patients infected with genotype C HBV. Sixty patients $(46.5 \%)$ were classified as F1, fourteen $(10.9 \%)$ as F2, seven $(5.4 \%)$ as F3, and six $(4.7 \%)$ as F4, including cirrhosis. No or insignificant fibrosis (fibrosis stage $<2$ ) was found in 102 patients (79.1\%); significant fibrosis (stage 2) was found in 27 patients $(20.9 \%$ ), and advanced fibrosis (stage 3 to 4 ) in 13 patients $(10.1 \%)$. The mean LSM value was $6.7 \pm 3.0 \mathrm{kPa}$, the average $\log _{10} \mathrm{HBsAg}(\mathrm{IU} / \mathrm{mL})$ was $4.3 \pm 0.9$, and the average $\log _{10}$ HBV DNA (copies/mL) was 7.5 \pm 1.2 .

\section{Univariate and multivariate analyses of variables to identify independent factors for screening for no or insignificant fibrosis}

Variables associated with no or insignificant fibrosis were first assessed by univariate analysis. Subsequent multivariate analysis revealed that the LSM value $(P<0.001$, odds ratio $14.67,95 \%$ confidence interval $0.158-0.551)$ and serum $\log _{10}$ HBsAg level $(P=0.045$, odds ratio $4.03,95 \%$ confidence interval 0.136-0.976) were independent factors indicating no or insignificant fibrosis (Table 2).

Table I Patients' baseline characteristics

\begin{tabular}{ll}
\hline Characteristics & Mean \pm SD or $\mathbf{n}(\%)$ \\
\hline Age (years) & $31.5 \pm 6.6$ \\
Male/female & $93(72.1) / 36(27.9)$ \\
Genotype B/C & $87(67.4) / 42(32.6)$ \\
Stage of fibrosis* & \\
F0 & $42(32.6)$ \\
FI & $60(46.5)$ \\
F2 & $14(10.9)$ \\
F3 & $7(5.4)$ \\
F4 & $6(4.7)$ \\
Log ${ }_{10} \mathrm{HBV} D N A($ copies $/ \mathrm{mL})$ & $7.5 \pm I .2$ \\
ALT (IU/L) & $32.3 \pm I 7.7$ \\
LSM $(\mathrm{kPa})$ & $6.7 \pm 3.0$ \\
Log $_{10} \mathrm{HBsAg}(\mathrm{IU} / \mathrm{mL})$ & $4.3 \pm 0.9$ \\
\hline
\end{tabular}

Notes: *Stage of fibrosis was evaluated according to the METAVIR scoring system. Abbreviations: ALT, alanine aminotransferase; DNA, deoxyribonucleic acid; F0, no fibrosis; Fl, portal fibrosis without septa; F2, portal fibrosis with few septa; F3, numerous septa without cirrhosis; $\mathrm{F}$, cirrhosis; $\mathrm{HBsAg}$, hepatitis $B$ surface antigen; $H B V$, hepatitis B virus; LSM, liver stiffness measurement; SD, standard deviation. 
Table 2 Univariate and multivariate analyses of variables to identify independent factors for screening for no or insignificant fibrosis

\begin{tabular}{|c|c|c|c|c|}
\hline \multirow[t]{2}{*}{ Variable } & \multirow{2}{*}{$\begin{array}{l}\text { No or insignificant } \\
\text { fibrosis }(n=109)\end{array}$} & \multirow{2}{*}{$\begin{array}{l}\text { Significant fibrosis or } \\
\text { cirrhosis }(n=20)\end{array}$} & \multicolumn{2}{|l|}{$P$-value } \\
\hline & & & Univariate analysis & Multivariate analysis \\
\hline Age (years), mean \pm SD & $32.6 \pm 6.7$ & $3 I . I \pm 6.2$ & 0.772 & 0.201 \\
\hline Male, n (\%) & $65(64.4 \%)$ & $20(76.9 \%)$ & 0.065 & 0.269 \\
\hline Genotype B, n (\%) & $68(67.3 \%)$ & $22(84.6 \%)$ & 0.802 & 0.912 \\
\hline $\operatorname{ALT}(\mathrm{IU} / \mathrm{L})$, mean $\pm \mathrm{SD}$ & $33.5 \pm 17.7$ & $26.5 \pm 17.1$ & 0.107 & 0.761 \\
\hline LSM $(\mathrm{kPa})$, mean $\pm \mathrm{SD}$ & $6.1 \pm 2.0$ & $11.7 \pm 3.4$ & $<0.001$ & $<0.001$ \\
\hline $\log _{10} \mathrm{HBV}$ DNA (copies/mL), mean \pm SD & $7.4 \pm 1.2$ & $7.7 \pm 1.0$ & 0.981 & 0.674 \\
\hline $\log _{10} \mathrm{HBsAg}(\mathrm{IU} / \mathrm{mL})$, mean $\pm \mathrm{SD}$ & $4.4 \pm 0.8$ & $3.5 \pm 1.2$ & $<0.001$ & 0.045 \\
\hline
\end{tabular}

Abbreviations: ALT, alanine aminotransferase; DNA, deoxyribonucleic acid; $\mathrm{HBs} A$, hepatitis $B$ surface antigen; $\mathrm{HBV}$, hepatitis $B$ virus; LSM, liver stiffness measurement; SD, standard deviation.

\section{Association of histological fibrosis stage and LSM value or HBsAg level}

The mean LSM value of all 129 patients was $6.7 \pm 3.0 \mathrm{kPa}$ (range, $3.2-18.6 \mathrm{kPa}$ ). The majority of patients (114 of 129 , $88.4 \%$ ) had LSM values under $9.4 \mathrm{kPa}$, which indicates no or insignificant fibrosis. A moderate inverse association was found between LSM value and $\log _{10} \mathrm{HBsAg}$ (correlation coefficient $-0.576, P<0.001$ ), as shown in Figure 1A. Also, an inverse correlation between $\log _{10} \mathrm{HBsAg}$ and liver fibrosis score (correlation coefficient $-0.374, P<0.001$ ) was observed. Patients with a fibrosis score $<\mathrm{F} 2$ had significantly higher $\log _{10} \mathrm{HBsAg}$ values than patients with a fibrosis score $\geq \mathrm{F} 2$ (4.4 \pm 0.8 vs $3.5 \pm 1.2, P<0.001$ ), as shown in Figure $1 \mathrm{C}$.

There were 114 patients $(88.4 \%$ ) with an LSM value under $9.4 \mathrm{kPa}$ (which indicates no or insignificant fibrosis), and 15 patients (11.6\%) had an LSM value equal to or greater than $9.4 \mathrm{kPa}$. According to the recommendations of the Review Panel for Liver Stiffness Measurement of China, ${ }^{19}$ an LSM value between 7.4 and $9.4 \mathrm{kPa}$ may suggested early fibrosis and should be considered an indication for liver biopsy if possible. We found that in 114 patients with LSM values under $9.4 \mathrm{kPa}$, there were 42 patients (36.8\%) with a fibrosis score of F0, 57 patients $(50 \%)$ with a fibrosis score of $\mathrm{F} 1,13$ patients (11.4\%) with a fibrosis score of F2, and two patients (1.8\%) with a fibrosis score of F3. In the 114 patients with LSM values under $9.4 \mathrm{kPa}$, those with a fibrosis score $<\mathrm{F} 2$ also had significantly higher $\log _{10} \mathrm{HBs} \mathrm{Ag}$ values than patients with a fibrosis score $\geq \mathrm{F} 2(4.6 \pm 0.7$ vs $4.3 \pm 0.5, P=0.006)$, as shown in Figure 1D. An inverse correlation between $\log _{10} \mathrm{HBsAg}$ and LSM value (correlation coefficient $r=-0.443, P<0.001$ ) was found, as shown in Figure 1B.

\section{Predictive value of $\mathrm{HBsAg}$ for minimal liver fibrosis changes}

A $\log _{10} \mathrm{HBsAg}$ value of greater than 4.02 (approximately $10,400 \mathrm{IU} / \mathrm{mL}$ ) had a sensitivity of $81 \%$ and specificity of
$70.0 \%$ for predicting no or insignificant fibrosis (stage $<\mathrm{F} 2$; area under the curve $[\mathrm{AUC}]=0.758, P<0.001,95 \%$ confidence interval $0.631-0.884$ ), with a positive predictive value of $73 \%$ and negative predictive value of $79 \%$ (Figure 2).

\section{Discussion}

Liver disease that develops out of chronic HBV infection is responsible for approximately 1 million deaths annually. ${ }^{1}$ Unfortunately, a standard approach for managing liver fibrosis has yet to be established. Liver transplantation is currently considered as both a primary and complementary measure for the treatment of this serious disease; however, the current shortage of donors does not permit extensive use of this treatment strategy. Therefore, elucidating the mechanism by which HBV infection leads to this disease in order to develop better methods for diagnosing patients during the early stages of the disease as well as to establish effective therapeutic strategies is a research priority.

With the availability of newly automated quantitative assays, the expression of its titers in standardized international units, such as the HBsAg titer, has become a new and important marker for assessing prognosis and therapeutic efficacy in chronic HBV infection. ${ }^{21}$ However, the possible association between quantitative HBsAg and liver fibrosis had not been fully discovered. The present study found an inverse correlation between the quantitative serum HBsAg level and liver histological fibrosis score in the $\mathrm{HBe} A g$-positive phase, as other investigators have previous described. ${ }^{17,18}$ Although the exact mechanism of the inverse association between the quantitative serum HBsAg titer and the staging of liver fibrosis is not fully understood, it may be related to the fact that patients with different levels of serum HBsAg are in the different stages of immune clearance. It is well-established that the serum HBsAg level is higher in the immune tolerance phase than in the immune clearance phase. ${ }^{22,23}$ With the transition from the immune tolerance 

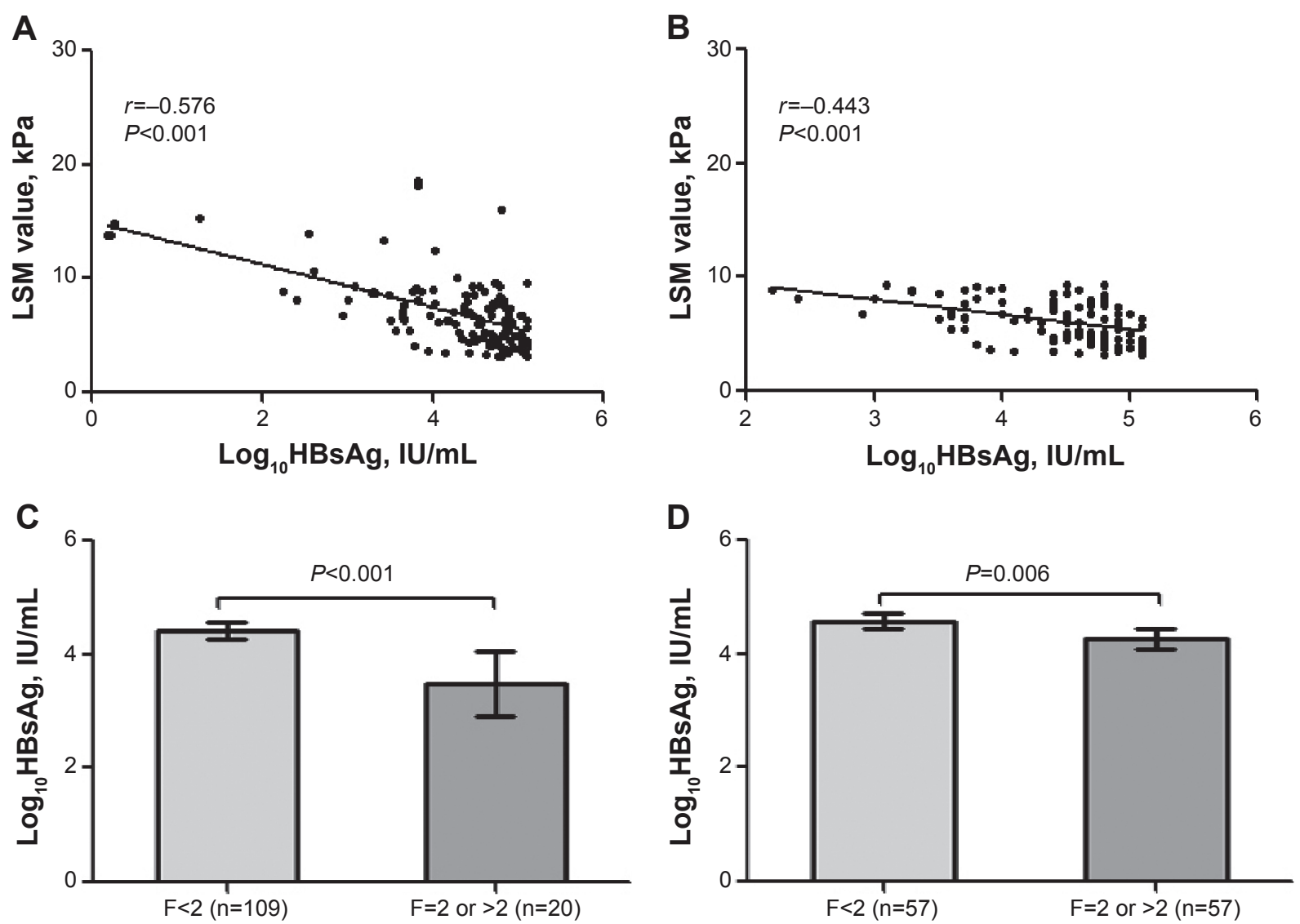

Figure I (A) The correlation between LSM value; (B) $\log _{10} \mathrm{HBsAg}$ in all 129 patients; (C) comparisons of $\log _{10} \mathrm{HBs} \mathrm{Ag}$ values in different stages (liver fibrosis score divided by fibrosis score $<F 2$ or $\geq F 2$ ) in all 129 patients; and (D) II 4 patients with a LSM value under $9.4 \mathrm{kPa}$.

Abbreviations: $\mathrm{HBs} A g$, hepatitis $B$ surface antigen; LSM, liver stiffness measurement.

phase to the early immune clearance phase, the intensity of the immune control on cccDNA in hepatocytes begins to increase. In the early immune clearance phase, the HBsAg levels can remain high, and there will be mild fibrosis due to the low magnitude of the immune-mediated attack. With the increase in the magnitude of the immune attack on the virus and hepatocytes entering into a more full-blown immune clearance stage, it is to be expected that more fibrosis will develop and serum HBsAg levels will decrease. In addition, the serum HBsAg level also can be influenced by the development of preS/S mutants and intracellular block of HBsAg secretion in the immune clearance phase. ${ }^{24}$

The association and comparison between quantitative HBsAg titer and other methods, which are already available for assessing fibrosis (such as liver transient elastography), had not been studied until recently. In the present study, we found a moderate inverse correlation between HBsAg and the LSM value in $\mathrm{HBeAg}$-positive patients. Among 114 patients with LSM values under $9.4 \mathrm{kPa}$, patients with a fibrosis score $<$ F2 also had a significantly higher $\log _{10} \mathrm{H}-$ BsAg than patients with a fibrosis score $\geq F 2(4.6 \pm 0.7$ vs
$4.3 \pm 0.5, P=0.006$ ), indicating that among patients with a low LSM value, those with a lower HBsAg titer are more likely to have early stage liver fibrosis. Because the LSM has limited diagnostic accuracy for early fibrosis, it is important to find a new method for screening for minimal fibrosis in the early stage, in order to reduce the need for liver biopsy. HBsAg titer might be helpful in supporting liver transient elastography in the screening of patients who may be more likely to develop fibrosis. Moreover, the combination of the quantitative serum HBsAg titer and liver transient elastography may represent a new, noninvasive, and effective strategy for assessing liver fibrosis.

Few studies have investigated the association between HBsAg titer and liver fibrosis until recently. Seto et al studied 140 patients in Hong Kong (65\% male, median age 32.7 years), of whom $56(40 \%)$ had an ALT $<2 \times$ ULN..$^{18}$ The study showed that patients with a fibrosis score $\leq \mathrm{F} 1$, in comparison to patients with a fibrosis score $>\mathrm{F} 1$, had significantly higher median HBsAg levels. Moreover, among patients with an ALT $<2 \times$ ULN, serum HBsAg levels achieved a ROC analysis value of 0.869 in predicting fibrosis score $\leq \mathrm{F} 1$. 


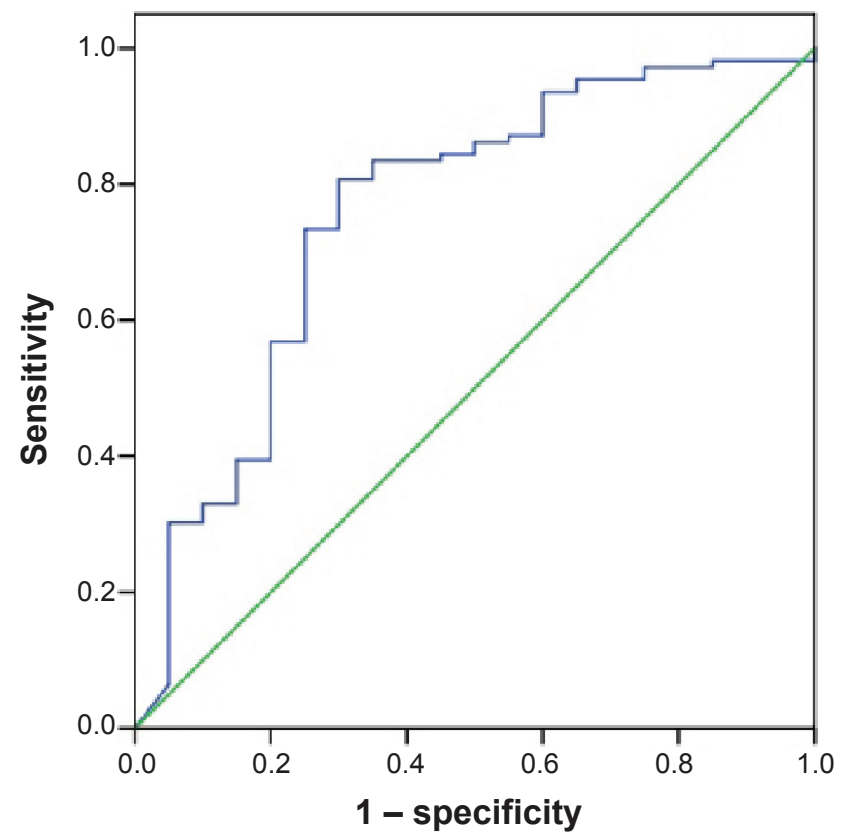

Figure 2 Receiver operating characteristic curves of $\log _{10} \mathrm{HBs} \mathrm{Ag}$ values for predicting no or insignificant fibrosis $(<\mathrm{F} 2)$.

Abbreviation: $\mathrm{HBsAg}$, hepatitis $B$ surface antigen.

HBsAg $\geq 25,000 \mathrm{IU} / \mathrm{mL}$ was independently associated with a fibrosis score $\leq \mathrm{F} 1(P=0.025$, odds ratio 9.042). However, differences between HBV genotypes were not assessed in the study, and HBeAg-negative patients were not included. The genotypes of all patients were detected in our study, and we found that HBsAg titers were comparable between genotypes B and C. The AUC acquired in our study was somehow weaker than that reported by Seto et al. This may be due to the fact that our study included HBeAg-negative patients, which weakened the correlation. Another reason may be that we did not stratify patients according to the ALT level as Seto et al did.

Our study has several limitations. First, it was a crosssectional investigation, and some researchers have found that high HBsAg is not always favorable in chronic HBV infection, as shown in two studies that reported an association between a high HBsAg level and the development of hepatocellular carcinoma ${ }^{25}$ and disease progression. ${ }^{26}$ Therefore, longitudinal studies are needed to further explore the exact relationship between the quantitative HBsAg titer and liver fibrosis. Secondly, the number of HBeAg-negative patients included in our study was small; studies including large numbers of HBeAgnegative patients are needed to confirm our findings.

Liver biopsy is also an important step in the evaluation of a patient with liver fibrosis and is required to formulate a diagnosis, direct therapy, and provide an accurate prognosis.
However, the risk/benefit ratio for performance of liver biopsy must be considered for every case individually. Although the chance of serious complications is low for a specific case or procedure, there is always the potential for complications to occur. Therefore, liver biopsy is generally only available in tertiary referral centers and academic institutions such as our hospital, and it provides important information on the status of the liver. Only after the clinical information, liver biopsy, and histopathology are obtained can a diagnosis be made and a prognosis determined. Although the operator must have proper training and adequate experience, liver biopsy remains an important diagnostic tool.

\section{Conclusion}

In this cross-sectional study based on a Chinese population, we found inverse correlations between the quantitative serum HBsAg level and liver transient elastography results as well as histological fibrosis score in HBeAg-positive patients. A high level of serum HBsAg titer correlated with a liver fibrosis score $<\mathrm{F} 2$ independently in multivariate analysis. Measurement of serum HBsAg levels can thus assist the assessment of liver fibrosis and potentially reduce the need for liver biopsy in HBeAg-positive patients.

\section{Acknowledgments}

This research was supported by the National Twelve-Five Project of China, and no benefits in any form have been or will be received from a commercial party directly or indirectly related to the subject of this article.

\section{Author contributions}

All authors conceived and designed the study. Ling-Bo Liang, Xia Zhu, Li-Bo Yan, and Juan Liao acquired the data and performed liver transient elastography. Cong Liu and Li-Yu Chen performed liver biopsy and prepared liver biopsy specimens. Ling-Bo Liang and Ling-Yao Du carried out the statistical analysis. All authors took part in either drafting the article or revising it critically for important intellectual content and gave final approval of the version to be published.

\section{Disclosure}

The authors report no conflicts of interest in this work.

\section{References}

1. Kao JH, Chen DS. Global control of hepatitis B virus infection. Lancet Infect Dis. 2002;2(7):395-403.

2. Lu FM, Li T, Liu S, Zhuang H. Epidemiology and prevention of hepatitis B virus infection in China. J Viral Hepat. 2010;17(Suppl 1): 4-9. 
3. Harrison TJ. Hepatitis B virus: molecular virology and common mutants. Semin Liver Dis. 2006;26(2):87-96.

4. Werle-Lapostolle B, Bowden S, Locarnini S, et al. Persistence of cccDNA during the natural history of chronic hepatitis B and decline during adefovir dipivoxil therapy. Gastroenterology. 2004;126(7): $1750-1758$.

5. Chan HL, Wong VW, Tse AM, et al. Serum hepatitis B surface antigen quantitation can reflect hepatitis B virus in the liver and predict treatment response. Clin Gastroenterol Hepatol. 2007;5(12):1462-1468.

6. Chan HL, Thompson A, Martinot-Peignoux M, et al. Hepatitis B surface antigen quantification: why and how to use it in 2011 - a core group report. J Hepatol. 2011;55(5):1121-1131.

7. Thompson AJ, Nguyen $\mathrm{T}$, Iser $\mathrm{D}$, et al. Serum hepatitis B surface antigen and hepatitis $\mathrm{B}$ e antigen titers: disease phase influences correlation with viral load and intrahepatic hepatitis B virus markers. Hepatology. 2010; 51(6):1933-1944.

8. Sonneveld MJ, Zoutendijk R, Janssen HL. Hepatitis B surface antigen monitoring and management of chronic hepatitis B. J Viral Hepat. 2011; 18(7):449-457.

9. Chan HL, Wong GL, Wong VW. A review of the natural history of chronic hepatitis B in the era of transient elastography. Antivir Ther. 2009; 14(4):489-499.

10. Bravo AA, Sheth SG, Chopra S. Liver biopsy. $N$ Engl J Med. 2001; 344(7):495-500

11. Zeng MD, Lu LG, Mao YM, et al. Prediction of significant fibrosis in $\mathrm{HBeAg}$-positive patients with chronic hepatitis B by a noninvasive model. Hepatology. 2005;42(6):1437-1445.

12. Fung J, Lai CL, Fong DY, Yuen JC, Wong DK, Yuen MF. Correlation of liver biochemistry with liver stiffness in chronic hepatitis B and development of a predictive model for liver fibrosis. Liver Int. 2008;28(10): 1408-1416.

13. Seto WK, Lee CF, Lai CL, et al. A new model using routinely available clinical parameters to predict significant liver fibrosis in chronic hepatitis B. PLoS One. 2011;6(8):e23077.

14. Friedrich-Rust M, Ong MF, Martens S, et al. Performance of transient elastography for the staging of liver fibrosis: a meta-analysis. Gastroenterology. 2008;134(4):960-974.

15. Chon YE, Choi EH, Song KJ, et al. Performance of transient elastography for the staging of liver fibrosis in patients with chronic hepatitis B: a meta-analysis. PLoS One. 2012;7(9):e44930.
16. Degos F, Perez P, Roche B, et al; FIBROSTIC study group. Diagnostic accuracy of FibroScan and comparison to liver fibrosis biomarkers in chronic viral hepatitis: a multicenter prospective study (the FIBROSTIC study). J Hepatol. 2010;53(6):1013-1021.

17. Martinot-Peignoux M, Carvalho-Filho R, Lapalus M, et al. Hepatitis B surface antigen serum level is associated with fibrosis severity in treatment-naïve, e antigen-positive patients. J Hepatol. 2013;58(6): 1089-1095.

18. Seto WK, Wong DK, Fung J, et al. High hepatitis B surface antigen levels predict insignificant fibrosis in hepatitis $\mathrm{B}$ e antigen positive chronic hepatitis B. PLoS One. 2012;7(8):e43087.

19. Wong GL, Wong VW, Choi PC, et al. Clinical factors associated with liver stiffness in hepatitis B e antigen-positive chronic hepatitis B patients. Clin Gastroenterol Hepatol. 2009;7(2):227-233.

20. Review Panel for Liver Stiffness Measurement. [Recommendations for the clinical application of transient elastography in liver fibrosis assessment]. Zhonghua Gan Zang Bing Za Zhi. 2013;21(6):420-424. Chinese.

21. Rotman Y, Brown TA, Hoofnagle JH. Evaluation of the patient with hepatitis B. Hepatology. 2009;49(5 Supp1):S22-S27.

22. Jaroszewicz J, Calle Serrano B, Wursthorn K, et al. Hepatitis B surface antigen (HBsAg) levels in the natural history of hepatitis B virus (HBV) infection: a European perspective. J Hepatol. 2010;52(4):514-522.

23. Nguyen T, Thompson AJ, Bowden S, et al. Hepatitis B surface antigen levels during the natural history of chronic hepatitis B: a perspective on Asia. J Hepatol. 2010;52(4):508-513.

24. Pollicino T, Amaddeo G, Restuccia A, et al. Impact of hepatitis B virus (HBV) $\mathrm{preS} / \mathrm{S}$ genomic variability on HBV surface antigen and HBV DNA serum levels. Hepatology. 2012;56(2):434-443.

25. Tseng TC, Liu CJ, Yang HC, et al. High levels of hepatitis B surface antigen increase risk of hepatocellular carcinoma in patients with low HBV load. Gastroenterology. 2012;142(5):1140-1149.e3; quiz e13.

26. Tseng TC, Liu CJ, Yang HC, et al. Serum hepatitis B surface antigen levels help predict disease progression in patients with low hepatitis B virus loads. Hepatology. 2013;57(2):441-450.
Therapeutics and Clinical Risk Management

\section{Publish your work in this journal}

Therapeutics and Clinical Risk Management is an international, peerreviewed journal of clinical therapeutics and risk management, focusing on concise rapid reporting of clinical studies in all therapeutic areas outcomes, safety, and programs for the effective, safe, and sustained use of medicines. This journal is indexed on PubMed Central, CAS,

\section{Dovepress}

EMBase, Scopus and the Elsevier Bibliographic databases. The manuscript management system is completely online and includes a very quick and fair peer-review system, which is all easy to use. Visit http://www.dovepress.com/testimonials.php to read real quotes from published authors. 